Jurnal Pemberdayaan: Publikasi Hasil Pengabdian kepada Masyarakat

Vol. 2, No. 2, Agustus 2018, Hal. 305-314

ISSN: 2088 4559; e-ISSN: XXXX-XXXX

DOI:

\title{
PEMBERDAYAAN KELOMPOK PENGELOLA UMKM DENGAN KETERAMPILAN GO ONLINE UNTUK MENINGKATKAN KUALITAS PENGELOLAAN
}

\author{
Supriyanto, Muhammad Najih Farihanto, Sugeng Handoko \\ Universitas Ahmad Dahlan, Yogyakarta \\ Email: supriyanto@tif.uad.ac.id
}

\begin{abstract}
ABSTRAK
Usaha Micro Kecil Menengah (UMKM) berkembang cukup pesat, artinya pemberdayaan masyarakat agar mandiri berjalan dengan baik. Kemampuan UMKM untuk dapat bertahan di jaman serba digital saat ini sangat penting untuk menopang keberlangsungan unit usahanya. Terlebih lagi UMKM yang ada di daerah pedesaan, sangat diperlukan penyuluhan, pelatihan, dan pendampingan untuk dapat GO Online. UMKM dilatih agar Siap Digital yaitu dapat menggunakan teknologi-teknologi digital yang ada saat ini untuk meningkatkan kualitas pengelolaan. Selain itu juga dapat digunakan sebagai media promosi dan penjualan produk maupun jasa UMKM. Setelah UMKM Siap Digital dilanjutkan dengan pendampingan untuk memilih teknologi yang tepat sehingga pemanfaatan teknologi dapat benar-benar efektif dan efisien. Kegiatan Pelatihan GO Online diharapkan dapat meningkatkan kualitas pengelolaan UMKM, serta mampu memaksimalkan teknologi untuk memaksimalkan marketing.
\end{abstract}

Kata kunci : umkm, go online, teknologi digital, marketing

\begin{abstract}
UMKM are developing quite rapidly, meaning that community empowerment to run well. The ability of UMKM to be able to survive in today's digital era is very important to sustain the sustainability of its business units. Moreover, UMKM in rural areas are very much needed for counseling, training and assistance to get GO Online. UMKM are trained so that Digital Ready can use digital technologies that exist today to improve management quality. Besides that, it can also be used as a media for promotion and sales of UMKM products and services. After Digital Ready, UMKM continue with assistance to choose the right technology so that the use of technology can be truly effective and efficient. GO Online Training Activities are expected to improve the quality of UMKM management, and be able to maximize technology.
\end{abstract}

Keywords:: umkm, go online, digital technologi, marketing 


\section{PENDAHULUAN}

Perkembangan UMKM berjalan cukup pesat di beberapa desa wilayah Gunungkidul D.I.Yogyakarta. Salah satu contohnya desa-desa yang berada di Kecamatan Patuk Gunungkidul. UMKM ini bermunculan dari hasil pelatihan-pelatihan pemberdayaan masyarakat untuk berkreasi mengolah bahan-bahan dasar hasil kekayaan desanya menjadi barang atau jasa yang dapat menghasilkan. Namun beberapa UMKM masih kesulitan untuk memajukan usahanya.

Ada beberapa faktor yang menjadi penyebabnya, salah satunya adalah kemampuan pengelolaan. Para pengelola UMKM di daerah pedesaan tidak memiliki sumber daya manusia yang cukup untuk mengelola lebih professional seperti manajemen produksi, manajemen karyawan marketing, dan lain sebagainya.

Teknologi digital yang berkembang cukup pesat telah menghasilkan teknologiteknologi yang memudahkan manusia. Pemanfaatan teknologi dalam bidang manajemen sudah sangat canggih dan mudah digunakan. Apalagi didukung oleh teknologi internet yang memeadai untuk melakukan transfer data dengan cepat. Teknologi digital dengan berbagai jenis mulai bermunculan, bahkan media sosial mulai bertambah fungsinya yaitu sebagai media marketing dan transaksi jual beli secara daring. Sebut saja teknologi cloud, yang memungkinkan penyimpanan data tanpa harus memiliki perangkat penyimpanan sendiri. Cloud juga memungkinkan terjadinya kolaborasi antar pengguna internet dalam pengerjaan suatu pekerjaan tertentu.

Pertumbuhan pengguna internet di Indonesia pada tahun 2017 sudah mencapai 143 juta. Komposisi pengguna berdasarkan usia paling tinggi pada rentang 19 - 34 tahun yaitu 49,52\% diikuti rentang umur 35 - 54 yaitu 29,55\% (Asosiasi Penyelenggara Jasa Internet Indonesia APJII, 2017). Berdasarkan data tersebut, dapat disimpulkan bahwa sebagian pengguna internet adalah usia produktif dan matang secara ekonomi. Data lain menunjukkan bahwa penggunaan internet sebagian menggunakan perangkat mobile dan mengakses media sosial dan chatting. Hal ini menjadi peluang strategis untuk meningkatkan keberlangsungan usaha khususnya UMKM.

Pelaku bisnis daerah perkotaan tentu tidak asing dengan teknologi media digital yang ada, sehingga pelaku bisnis didaerah kota pasti mudah dalam mengoperasikan teknologiteknologi yang ada. Berbeda dengan pelaku bisnis (UMKM) di pedesaan, mereka belum terbiasa dengan adanya teknologi media digital yang ada. Apalagi, ragam teknologi media 
digital sangat banyak. Sumber daya manusia jelas sekali menjadi kendala pengelola UMKM tidak dapat terjun aktif ke dalam dunia digital dan daring.

Langkah pertama yang paling memungkinkan untuk masyarakat pedesaan adalah kesadaran akan pentingnya data dalam pengelolaan UMKM. Jika sudah memiliki kesadaran data, maka langkah selanjutnya adalah dengan memberikan pengetahuan tentang teknologi. Parapelaku UMKM harus mengenal teknologi yang ada dan mengerti fungsi serta manfaatnya. Para pelaku atau pengelola UMKM harus dapat menentukan dan memilih teknologi yang tepat untuk kebutuhan usahanya. Terakhir yang pelatihan dan pendampingan penggunaan teknologi-teknologi tersebut. Semua kegiatan tersebut dikemas dalam kegiatan yang berjudul Pelatihan Go Online untuk UMKM.

\section{METODE}

Seperti yang telah diuraikan sebelumnya bahwa kegiatan pelatihan ini dimulai dari seminar tentang pentingnya data dan jaringan dilanjutkan dengan kegiatan pengenalan, pelatihan dan pendampingan penggunaannya. Berdasarkan kebutuhan tersebut, maka metode yang digunakan dalam kegiatan ini adalah model seminar, pelatihan dan pendampingan. Model seminar digunakan untuk meningkatkan kesadaran masyarakat akan pentingnya data dan cara mengelola data dengan teknologi. Hal ini penting karena jika tidak dimulai dari kebutuhan, masyarakat nantinya justru akan terbebani dengan pengetahuan penggunaan teknologi yang nantinya digunakan. Model pelatihan harus dilengkapi dengan pendampingan.Pendampingan ini digunakan untuk memastikan bahwa para pelaku UMKM benar-benar mampu menggunakan teknologi digital.

Rincian materi yang diberikan saat pelatihan adalah sebagai berikut:

- Pelatihan penggunaan Email

Email atau surat elektronik (surel) menjadi hal yang wajib diketahui dan dimiliki oleh para pelaku bisnis. Surel menjadi kunci masuk untuk dapat terjun ke dalam dunia digital dan internet. Surel yang digunakan dalam kegiatan ini adalah Google Mail (Gmail). Gmail menjadi surel yang paling banyak digunakan saat ini.

- Pelatihan penggunaan Google My Business

Google My Business adalah salah satu layanan dari Google untuk memberikan identitas kepada suaatu tempat (khususnya tempat bisnis). Identitas yang dimunculkan lengkap mulai dari deskripsi, cara menghubungi, lokasi dalam map (peta digital), foto, bahkan sampai dengan review atau testimoni dari para pengguna internet lainnya. Dengan 
begitu, UMKM akan terindeks ke dalam mesin pencari google. Dampaknya, ketika ada yang mencari kata kunci yang mungkin berhubungan dengan UMKM tersebut, maka informasi Google My Business akan muncul di dalam hasil pencarian.

- Pelatihan penggunaan Facebook

Sosial media yang satu ini adalah salah satu media social yang paling konsisten. Anggotanya sudah juataan orang yang tersebar di seluruh penjuru dunia. Facebook memungkinkan para pengguna internet terhubung dengan mudah satu sama lain dengan berbagaimacam interaksi. Interaksi yang ditawarkan mulai dari forum, berbagi video, melakukan percakapan. Hal ini menjadi peluang yang bagus untuk dimanfaatkan dalam pengelolaan bisnis, contohnya menjadi lebih dekat dengan calon pelanggan dan pelanggan. Peluang lainnya yaitu promosi dan edukasi produk kepada masyarakat.

- Pelatihan penggunaan Instagram

Instagram saat ini mejadi anak perusahaan dari facebook. Instagram memberikan pengalaman bersosial media yang berbeda. Pada dasarnya Instagram hanyalah mengunggah foto dan video yang nantinya foto video ini dapat di follow, di like, dan di komentari oleh para pengguna internet lainnya. Hal ini dapat dijadikan peluang untuk dijadikan etalase produk atau layanan yang ditawarkan UMKM.

- Pelatihan penggunaan Link Tree

Link Tree adalah layanan teknologi daring yang bermanfaat untuk membuat link (jalur menuju sesuatu) di dalam informasi umum para pengguna internet. Contoh pemanfaatan link tree adalah memberikan informasi link website, alamat facebook, alamat email dalam satu tampilan link saja. Sehingga tidak membingungkan pengguna lain yang membaca. Link Tree menjadi media penting agar UMKM dapat lebih dikenal dan dijangkau dengan mudah oleh pelanggan maupun calon pelanggannya.

- Pelatihan strategi marketing

Strategi marketing sebenarnya masuk ke dalam agenda pendampingan. Bukan hanya strategi marketing saja, tetapi diajarkan pula bangaimana caranya membuat konten media social yang bagus dengan mudah. Kata kuncinya adalah mudah, sehingga pra pengelola UMKM tidak merasa terbebani dengan teknologi digital yang diajarkan.

\section{HASIL, PEMBAHASAN, DAN DAMPAK}

Kegiatan Go Online ini dilaksanakan di Kawasan wisata Gunung Api Purba Nglanggeran tepatnya di Pendopo Song Gudel. Kawasan ini dipilih karena memang 
POKDARWIS Nglanggeran adalah yang terdepan dalam sisi pemberdayaan masyarakatnya di Kecamatan Patuk bahkan skala Kabupaten Gunungkidul.

Pelaksanaan Go Online dibagi ke dalam 2 hari yaitu hari sabtu dan ahad. Hari pertama ditunjukkan oleh Gambar 1, diisi dengan kegiatan seminar, penyuluhan dan pelatihan dengan mengusung tema Siap Digital. Para pelaku UMKM diharapkan dapat benar-benar siap untuk tahap selanjutnya yaitu terjun ke dalam dunia digital dan daring. Materi hari pertama disampaikan oleh narasumber yang memiliki latar belakang teknologi informasi dari Teknik Informatika Universitas Ahmad Dahlan.

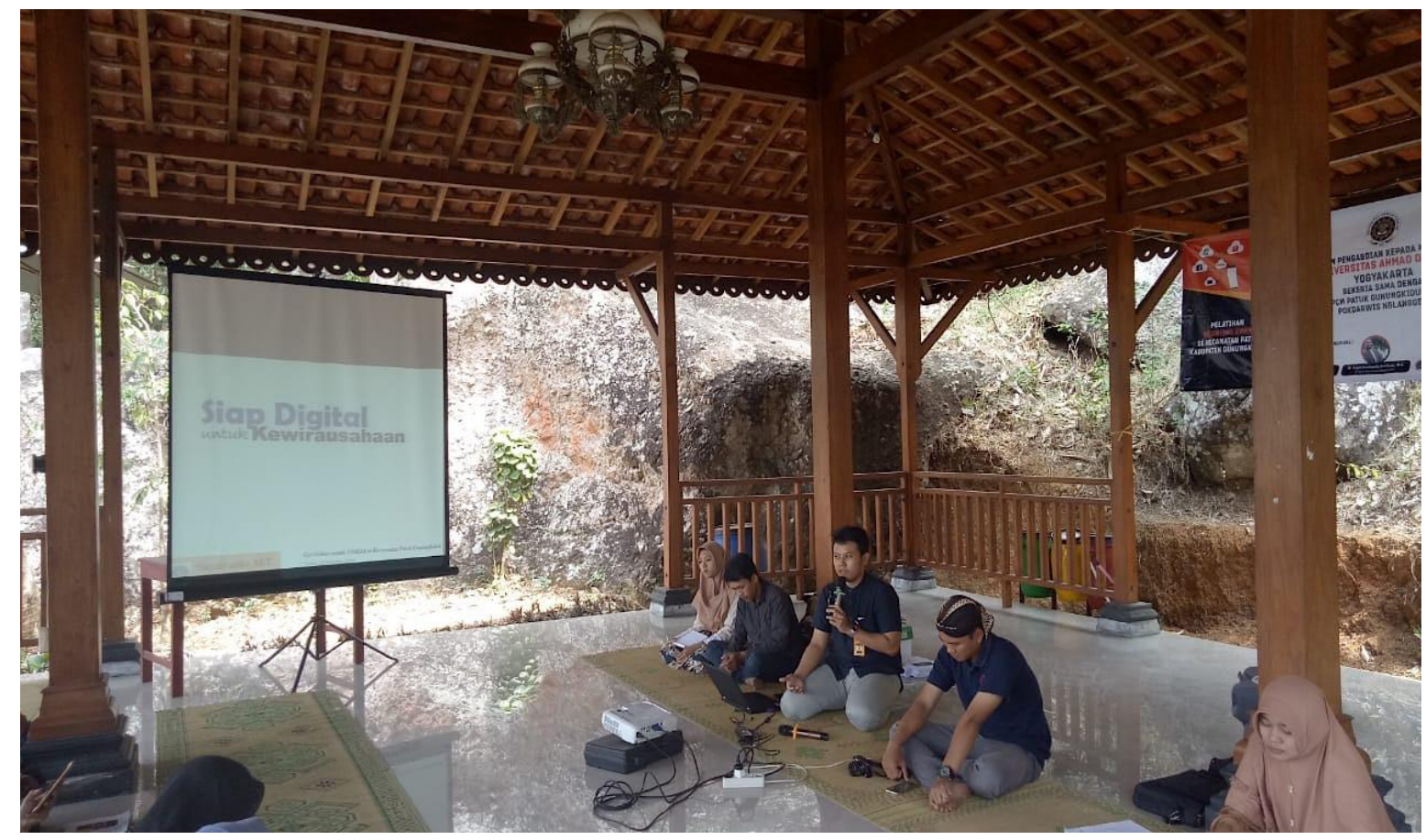

Gambar 1. Pelatihan Go Online hari pertama

Hari kedua ditunjukkan oleh Gambar 2, diisi dengan pelatihan pembuatan konten digital dan pelatihan strategi marketing. Urutan acara secara garis besar ditunjukkan oleh Tabel 1. Materi pelatihan hari kedua disampaikan oleh narasumber yang memiliki latar belakang ilmu komunikasi dari Ilmu Komunikasi Universitas Ahmad Dahlan. 


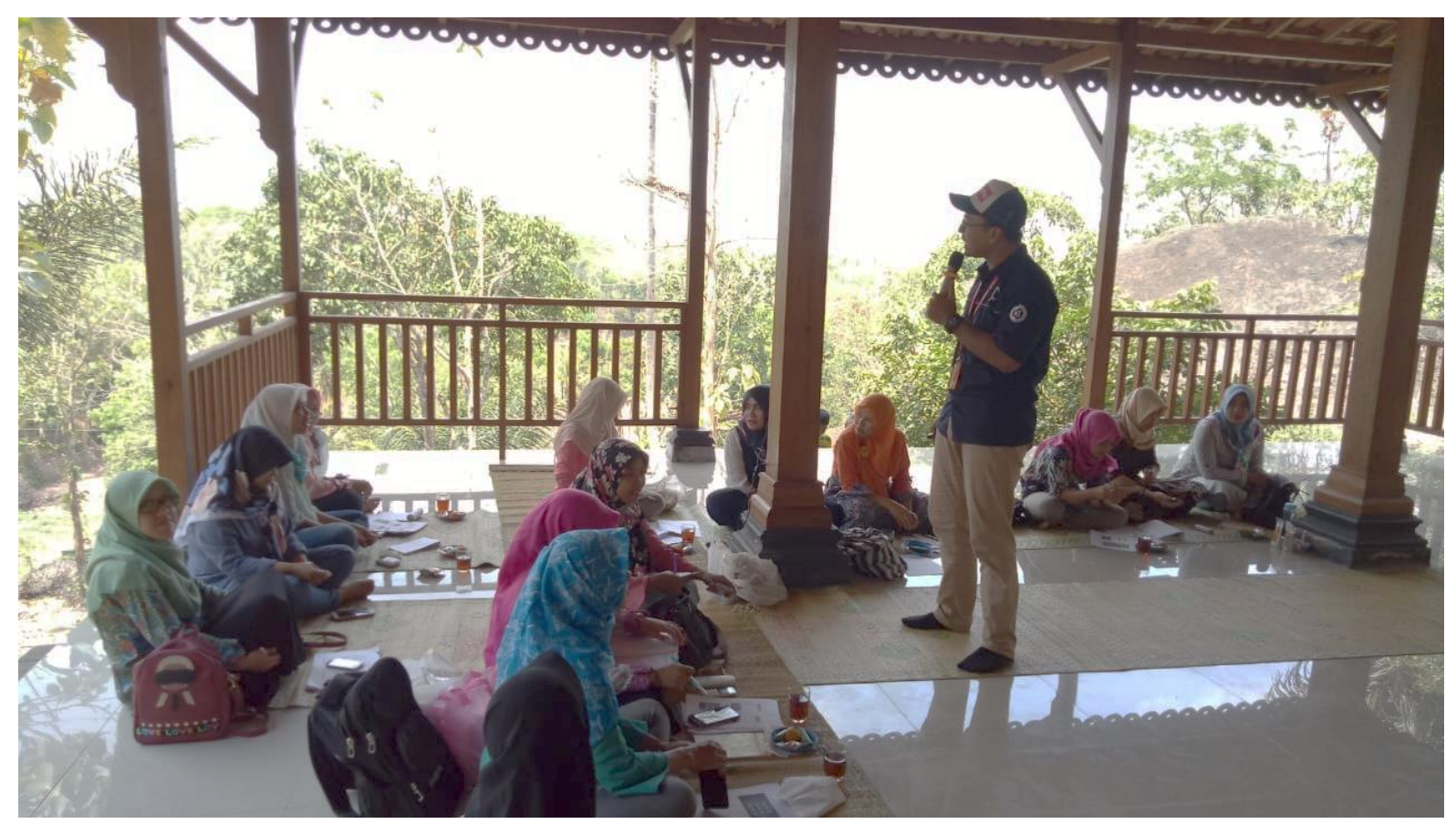

Gambar 2. Pelatihan Go Online hari kedua.

Para pelaku atau pengelola UMKM yang hadir adalah UMKM yang diundang ataupun mendaftar untuk mengikuti kegiatan ini. Hanya belasan UMKM yang hadir dari puluhan UMKM yang ada di Kecamatan Patuk. Salah satu penyebabnya adalah para pelaku UMKM yang sebagian besar masyarakat pedesaan merasa tidak percaya diri untuk belajar hal baru. Beberapa ketakutan yang muncul yaitu berkaitan dengan umur, tidak percaya diri dengan produknya dan yang paling penting adalah kesadaran untuk dapat terus berkembang.

UMKM yang hadir cukup beragam dari sisi jenis usahanya. Seperti ditunjukkan pada Tabel 2, mulai dari penyedia jasa, produk kecantikan, serta produk olahan makanan dan minuman. Peserta di dominasi oleh para pelaku olahan makanan dan minuman. Makanan dan minuman yang dihasilkan adalah hasil olahan hasil bumi yang ada di desanya. Terasa sekali kearifan lokal dari produk-produk UMKM. Kearifan lokal yang siap mendunia dengan Go Online. Bebrapa sudah ada yang terjun ke dunia digital, akan tetapi masih belum dapat memaksimalkan peran teknologi yang digunakan. Sebagai contoh, belum banyak jaringan di akun media sosialnya dan bahkan belum memberikan informasi yang lengkap.

Permasalahan dan semangat berkembang ini seharusnya menjadi perhatian. Masyarakat sudah mampu menghasilkan sesuatu yang memiliki nilai jual lebih dari hasil bumi yang ada di desanya. Potensi-potensi sudah mulai tergali, tetapi keberlanjutan ini belum menjadi perhatian. Kegiatan Go Online ini diharapkan dapat meningkatkan kualitas pengelolaan 
menjadi lebh baik, sehingga keberlanjutan UMKM dapat terus dijaga dan dikembangkan. Kemandirian masyarakat nantinya akan benar-benar terwujud.

Kegiatan Go Online benar-benar menuntut para peserta untuk terjun langsung dengan contoh kasus yang sebenarnya yaitu produk UMKM masing-masing. Pelatihan juga cukup mudah karena hanya menggunakan smartphone atau gawai masing-masing. Syaratnya dapat terkoneksi internet dengan baik dan lancer. Peserta diberikan fasilitas perdanan kartu GSM yang sudah berisi paket data. Bahasa penyampaian yang digunakan harus membaur dengan masyarakat pedesaan khususnya daerah Gunungkidul yaitu Bahasa jawa.

Rangkaian kegiatan telah dilaksanakan dengan baik dan berjalan lancar. Beberapa testimoni telah didapatkan berdasarkan kuesioner yang disebarkan. Sebagian besar memberikan apresiasi kepada tim dan narasumber. Para pengelola UMKM mulai tahu bagaimana cara memngembangkan bisnis dengan memanfaatkan teknologi agar dapat bersaing dengan pasar. Kesadaran ini yang penting, harapannya dapat menularkan pengetahuan dan kemampuannya kepada pengelola lainnya sehingga semakin banyak UMKM yang dapat berkembang.

Kegiatan selanjutnya adalah melakukan monitoring terhadap para pengelola UMKM yang mengikuti kegiatan Go Online. Selama kurang lebih pengamatan dan evaluasi selama satu bulan terlihat aktifitas para pengelola mulai meningkat. Hal ini terlihat dari kenaikan jumlah unggahan social medianya. Selain itu dapat terlihat dari jumlah pengikut atau jaringan yang didapatkan.

Sebagai contoh UMKM aneka kripik dan usaha warung sate kambing salah satu peserta. Terlihat pada Gambar 3 jumlah pengikutnya mencapai angka seratusan. Meningkat cukup signifikan dari jumlah sebelum mengikuti kegiatan Go Online. Selain itu juga terlihat dari kualitas foto, video dan deskripsi unggahannya. Semakin informatif dan mudah dipahami oleh para pengguna internet. 


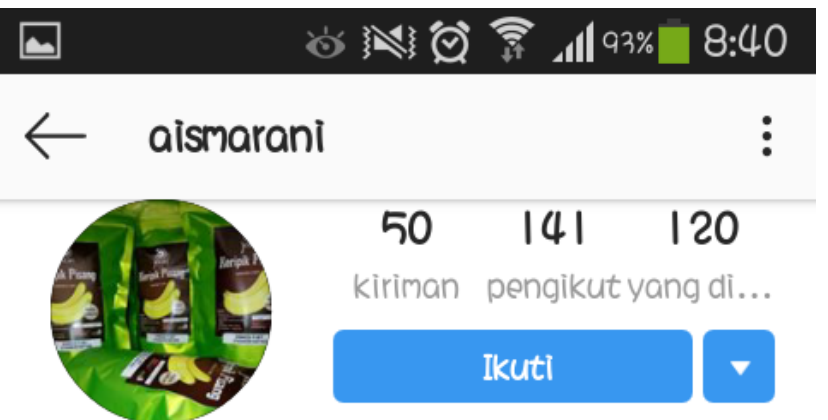

\section{ANEKA KRIPIK}

warung Sate Kambing \& aneka Keripik..

Order 082324299048

linktr.eelaismaranì

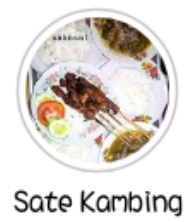

Gambar 3. Kutipan akun Instagram UMKM Aneka Keripik

Contoh berikutnya dari UMKM yang sebelumnya sudah memiliki akun media sosial juga memilki peningkatan pengikut dan jumlah unggahan seperti terlihat pada Gambar 4 . Akun UMKM kampung emas misalnya dengan produk ayam ingkung telah memiliki lebih dari seribu lima ratus pengikut dan tiga ratus unggahan.

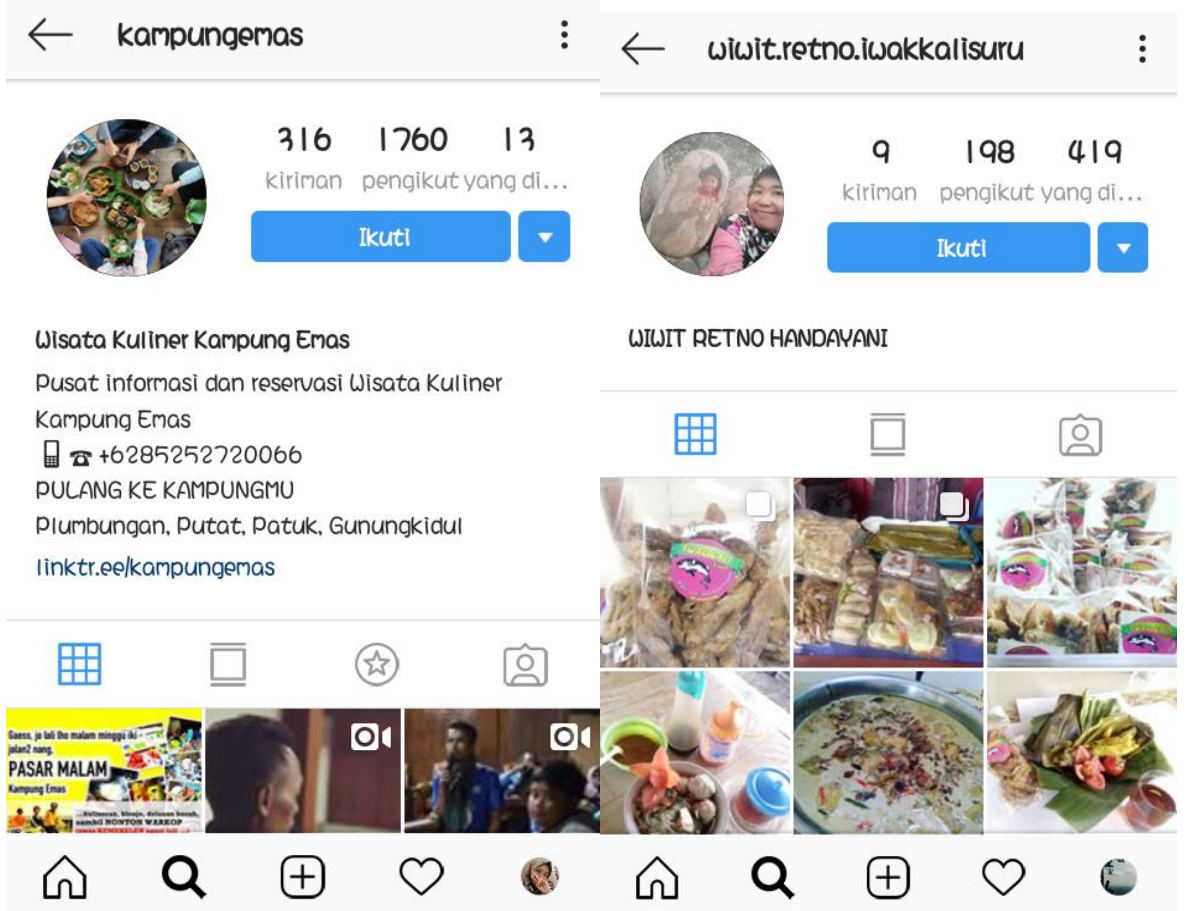


Gambar 4. Kutipan akun Kampung Emas dan Iwakkali

\section{KESIMPULAN}

Pelatihan Go Online telah dilaksanakan dengan baik, dan hasilnya peserta telah aktif di dunia maya dengan mengunggah konten-konten yang menarik. Keaktifan peserta terlihat dari jumlah unggahan di media sosial. Pelatihan Go Online terbukti dapat menjadi wadah edukasi untuk para pelaku UMKM desa untuk dapat bersaing di dunia digital.

\section{DAFTAR PUSTAKA}

Asosiasi Penyelenggara Jasa Internet Indonesia - APJII (2017). Penetrasi \& Perilaku Pengguna Internet Indonesia - Survey 2017, p. 34. Jakarta: APJII.

Hamzah, Y. I. et al. (2013). Potensi Media Sosial Sebagai Sarana Promosi Interaktif Bagi Pariwisata Indonesia' Jurnal Kepariwisataan Indonesia, 8(3), pp. 1-9. Available at: http://www.kemenpar.go.id/userfiles/JKI Vol_8 No_3 2013 - Potensi Media Sosial Sebagai Sarana Promosi Interaktif Bagi Pariwisata Indonesia.pdf.

Pamungkas, bagas aji and Zuhroh, S. (2016). Pengaruh Promosi Di Media Sosial Dan Word of Mouth Terhadap Keputusan Pembelian, Komunikasi, x(2), pp. 145-160.

Umami, Z. (2015). Social Strategy Pada Media Sosial Untuk Promosi Pariwisata Daerah Istimewa Yogyakarta, Jurnal Interaksi, 4(2), pp. 195-201. doi: 1014710/interaksi,4,2,195-201.

\section{UCAPAN TERIMAKASIH}

Ucapan terima kasih diberikan kepada Lembaga Penelitian dan Pengabdian kepada Masyarakat UAD yang telah mendanai kegiatan ini. Selanjutnya terimakasih disampaikan kepada Pimpinan Cabang Muhammadiyah Kecamatan Patuk Gunungkidul yang telah memebrikan rekomendasi. Terakhir ucapan terimakasih kepada POKDARWIS Nglanggeran 
2018 Jurnal Pemberdayaan: Publikasi Hasil Pengabdian kepada Masyarakat - ISSN: 2088 4559; e-ISSN:

yang bersedia menjadi mitra kegiatan dan mempersipakan fasilitas untuk kegiatan GO Online. 